British Journal of Nutrition (2022), 127, 782-790

(C) The Author(s), 2021. Published by Cambridge University Press on behalf of The Nutrition Society. This is an Open Access article, distributed under the terms of the Creative Commons Attribution licence (http://creativecommons.org/licenses/by/4.0/), which permits unrestricted re-use, distribution, and reproduction in any medium, provided the original work is properly cited.

\title{
The effects of different temperatures of post-exercise protein-containing drink on gastric motility and energy intake in healthy young men
}

\author{
Kyoko Fujihira $^{1}$, Yuka Hamada ${ }^{1}$, Miki Haramura ${ }^{1}$, Katsuhiko Suzuki ${ }^{2}$ and Masashi Miyashita ${ }^{2 *}$ \\ ${ }^{1}$ Graduate School of Sport Sciences, Waseda University, Saitama 359-1192, Japan \\ ${ }^{2}$ Faculty of Sport Sciences, Waseda University, Saitama 359-1192, Japan \\ (Submitted 4 January 2021 - Final revision received 18 March 2021 - Accepted 19 April 2021 - First published online 27 April 2021)
}

\section{Abstract}

The present study examined the effects of different temperatures of protein-containing drink after exercise on subsequent gastric motility and energy intake in healthy young men. Twelve healthy young men completed three, $1-\mathrm{d}$ trials in a random order. In all trials, the subjects ran on a treadmill for $30 \mathrm{~min}$ at $80 \%$ of maximum heart rate. In exercise + cold drink $\left(2^{\circ} \mathrm{C}\right)$ and exercise + hot drink $\left(60^{\circ} \mathrm{C}\right)$ trials, the subjects consumed $300 \mathrm{ml}$ of protein-containing drink $(0.34 \mathrm{MJ})$ at $2{ }^{\circ} \mathrm{C}$ or $60^{\circ} \mathrm{C}$ over a 5 -min period after exercise. In the exercise (i.e. no preload) trial, the subjects sat on a chair for $5 \mathrm{~min}$ after exercise. Then, the subjects sat on a chair for $30 \mathrm{~min}$ to measure their gastric motility with an ultrasound imaging system in all trials. Thereafter, the subjects consumed a test meal until they felt comfortably full. Energy intake in the exercise + hot drink trial was $14 \%$ and $15 \%$ higher than the exercise $(P=0 \cdot 046,95 \% \mathrm{CI} 4 \cdot 010,482 \cdot 538)$ trial and exercise + cold drink $(P=0 \cdot 001,95 \%$ CI $160 \cdot 089,517 \cdot 111)$ trial, respectively. The frequency of the gastric contractions in the exercise + hot drink trial was higher than the exercise $(P=0 \cdot 023)$ trial and exercise + cold drink $(P=0.007)$ trial. The total frequency of gastric contractions was positively related to energy intake $(r=0 \cdot 386, P=0 \cdot 022)$. These findings demonstrate that consuming protein-containing drink after exercise at $60^{\circ} \mathrm{C}$ increases energy intake and that this increase may be related to the modulation of the gastric motility.

Key words: Drink temperature: Exercise: Gastric motility: Appetite: Ultrasound imaging

According to a recent position paper on nutrition and exercise, protein intake in the early recovery phase after exercise is recommended to help improve muscle protein synthesis ${ }^{(1)}$. Although the protein-containing drinks after exercise are known to be useful for muscle recovery ${ }^{(2)}$, post-exercise proteincontaining ingestion has been reported to reduce energy intake compared with the carbohydrate-containing drinks ${ }^{(3,4)}$, but inconsistent results were also reported ${ }^{(5)}$.

To date, three laboratory-based studies have examined the effects of protein-containing drinks ingestion on subsequent energy intake in various individuals ${ }^{(3-5)}$, with discrepancies in the results. Monteyne et al. and Rumbold et al. showed that consuming a protein-containing drink after exercise reduced energy intake compared with consuming a carbohydrate-containing drink $^{(3,4)}$. Clayton et al. reported that consuming a proteincontaining drink after exercise reduced energy intake compared with a placebo drink, but did not differ from the carbohydratecontaining drink ${ }^{(5)}$. These studies vary in protocols including the amount of protein-containing drink ingested (i.e., 500-600 ml), the type of exercise (resistance exercise and aerobic exercise) and the type of protein-containing drink (whey protein isolate drink, skimmed milk and $6 \%$ whey protein isolate drink). Also, only one study clearly reported the drink temperature used in the study (i.e. about $\left.5^{\circ} \mathrm{C}\right)^{(4)}$. Although the reasons for these discrepancies among studies are unclear, the energy intake might be affected by the drink temperature. Although the effectiveness of internal thermal changes such as consuming cold drink after exercise on exercise performance and preventing dehydration has been addressed in previous studies ${ }^{(6)}$, no studies have investigated the effects of 'drink temperature' after exercise on energy intake. The rate of gastric emptying and the magnitude of gastric motility (i.e. measured via cross-sectional pyloric antral area reflecting gastric distention, rate of gastric emptying and frequency of gastric contractions) are known as one of the factors of appetite regulation after exercise ${ }^{(7)}$ and are influenced by the temperatures of consumed energycontaining drinks ${ }^{(8,9)}$. Indeed, Verhagen et al. showed that the frequency of gastric motility increased after a liquid meal at $37^{\circ} \mathrm{C}$ and $55^{\circ} \mathrm{C}$ compared with after a liquid meal at $4^{\circ} \mathrm{C}^{(8)}$. Also, Mishima et al. showed that the rate of gastric emptying was faster after a liquid and solid meal at $60^{\circ} \mathrm{C}$ compared with after a meal at $37^{\circ} \mathrm{C}^{(9)}$. Furthermore, our previous study has

Abbreviations: CA, coeliac artery; HRmax, maximum heart rate; MBV, mean blood velocity; PYY, plasma peptide YY; SMA, superior mesenteric artery.

*Corresponding author: Masashi Miyashita, email m.miyashita@waseda.jp 
demonstrated that pre-meal water ingestion at $2^{\circ} \mathrm{C}$ reduces subsequent energy intake compared with the water ingestion at $37^{\circ}$ $\mathrm{C}$ and $60^{\circ} \mathrm{C}$, and reduced energy intake after consuming cold water (i.e. at $2^{\circ} \mathrm{C}$ ) ingestion is accompanied by a change in gastric contractions ${ }^{(10)}$. Thus, the rationale behind the intention of the present study is based on these reported findings. Collectively, to our knowledge, no studies have examined the effects of different temperatures of a post-exercise proteincontaining drink on gastric motility and subsequent energy intake $^{(7)}$. Investigations in this area represent an important gap in current knowledge since adequate energy intake after exercise is critical in preventing low-energy availability conditions ${ }^{(11)}$.

The purpose of this study was to investigate the effects of different temperatures of protein-containing drink after exercise on gastric motility and subsequent energy intake in healthy young men. We hypothesised that consuming a protein-containing drink at $60^{\circ} \mathrm{C}$ would increase gastric motility and subsequent energy intake compared with consuming a protein-containing drink at $2^{\circ} \mathrm{C}$.

\section{Experimental methods}

\section{Subjects}

After approval from the Ethics Committee on Human Research of Waseda University (Approval number: 2019-016), twelve healthy young men gave written informed consent to participate in this study. This study was registered in advance with the University Hospital Medical Information Network Center, a system for registering clinical trials (ID: UMIN000036537). The physical and descriptive characteristics of the subjects are shown in Table 1. All subjects were non-smokers and were not taking any medicine, and their body masses had been stable for at least 3 months before the study.

\section{Standardisation of diet and physical activity}

In the $15 \mathrm{~h}$ before the first main trial, subjects were weighed and dietary intake was recorded. This dietary intake was replicated in the $15 \mathrm{~h}$ preceding the second and third main trials. Food diaries were analysed using software to determine energy intake and macronutrient content (Excel Eiyoukun version 5.0;

Table 1. Characteristics of the subjects

(Mean values and standard deviations, $n=12$ )

\begin{tabular}{|c|c|c|}
\hline Characteristics & Means & SD \\
\hline Age (years) & $24 \cdot 2$ & $2 \cdot 3$ \\
\hline Height $(\mathrm{m})$ & $1 \cdot 71$ & 0.04 \\
\hline Body mass (kg) & 65.9 & $6 \cdot 0$ \\
\hline BMI $\left(\mathrm{kg} / \mathrm{m}^{2}\right)$ & $22 \cdot 7$ & 1.6 \\
\hline Maximum oxygen uptake $(\mathrm{ml} / \mathrm{kg} / \mathrm{min})$ & 53.5 & $7 \cdot 7$ \\
\hline Smoker (\%) & 0 & \\
\hline Prescribed medicine intake (\%) & 0 & \\
\hline Current disease status (\%) & 0 & \\
\hline \multicolumn{3}{|l|}{ Daily drink intake per $1 \mathrm{~h}$} \\
\hline 0-200 ml (\%) & $63 \cdot 6$ & \\
\hline $201-400 \mathrm{ml}(\%)$ & $27 \cdot 3$ & \\
\hline $401-600 \mathrm{ml}(\%)$ & 0 & \\
\hline $601-800 \mathrm{ml}(\%)$ & $9 \cdot 1$ & \\
\hline
\end{tabular}

Kenpakusha). In addition, the subjects were asked to remain inactive for $1 \mathrm{~d}$ before each main trial. Subjects wore a uniaxial accelerometer (Lifecoder-EX; Suzuken Co. Ltd) to monitor daily activity the day before each main trial. The accelerometer defined 11 activity intensity levels $(0,0.5$ and 1-9) with 0 indicating the lowest intensity and 9 indicating the highest intensity. A level of 4 corresponds to an intensity of about 3 metabolic equivalents $^{(12)}$. The total step count (steps/d) was recorded and calculated from the accelerometer using software (Lifelyzer 05 Coach; Suzuken Co. Ltd).

\section{Study design}

The subjects underwent three, 1-d laboratory-based trials in random order: (1) exercise (i.e. no preload), (2) exercise + cold drink at $2^{\circ} \mathrm{C}$ and (3) exercise + hot drink at $60^{\circ} \mathrm{C}$. The interval between trials was at least $6 \mathrm{~d}$. All subjects were asked to maintain their normal eating habits among the trials and to refrain from vigorous exercise and alcohol intake for $24 \mathrm{~h}$ before each trial. Before the main trials, each subject underwent the preliminary tests to determine their maximum oxygen uptake $\left(\mathrm{VO}_{2 \max }\right)$ and maximum heart rate $\left(\mathrm{HR}_{\max }\right)$. Two preliminary exercise tests were performed as follows: (1) submaximal treadmill running test and (2) maximum oxygen uptake treadmill running test. After these preliminary tests, the subjects were given at $6 \mathrm{~d}$ to recover from the exercise testing before the first main trial began (11 (sD 6) days - the range from 6 to 29 d).

\section{Preliminary exercise tests}

After treadmill familiarisation, the subjects performed two preliminary exercise tests on a treadmill (JOG NOW 700; Technogym). The first test involved a 16-min treadmill running test to establish the relationship between treadmill running speed and oxygen uptake. Participants completed four, 4-min incremental stages with a starting at a speed of 7 or $8 \mathrm{~km} / \mathrm{h}$ and increasing by $1.5 \mathrm{~km} / \mathrm{h}$ every $4 \mathrm{~min}$. The treadmill set at $0 \%$ incline throughout. After resting for $15 \mathrm{~min}$, participants then completed a $\mathrm{VO}_{2 \max }$ test. Maximum oxygen uptake was measured directly using an incremental uphill protocol at a constant speed until the subjects reached volitional exhaustion ${ }^{(13)}$. The treadmill incline was initially set at 3.5\% and increased by $2.5 \%$ every $3 \mathrm{~min}$. Oxygen uptake, carbon dioxide production and respiratory exchange ratio were measured continuously throughout the tests using an online breath-by-breath gas analyser (Quark CPET; COSMED). Heart rate was measured continuously throughout the test using short range telemetry (Polar RCX3; Polar Electro). Ratings of perceived exertion were recorded at the end of each stage during both exercise tests using the Borg scale ${ }^{(14)}$. Criteria used to confirm a maximum value included two or more of the following: (1) heart rate $>95 \%$ of age-predicted $\mathrm{HR}_{\max }$, (2) respiratory exchange value $>1 \cdot 15$, (3) a plateau in oxygen consumption and (4) ratings of perceived exertion $\geq 19$.

\section{Experimental protocol}

On the day of each main trial day, subjects reported to the laboratory at 0850 after a 10-h overnight fast - subjects were allowed 
to drink only one glass of water no later than $2 \mathrm{~h}$ before each trial. Subjects ran on the treadmill for $30 \mathrm{~min}(09.00-09.30)$ at the running speed predicted to elicit $80 \%$ of $\mathrm{HR}_{\max }$ in all trials. Running speed was adjusted by target HR. The ratings of perceived exertion was recorded at 5-min intervals during the tests using the Borg scale ${ }^{(14)}$. Within 5 min after the running exercise (09.3009.35), subjects consumed $300 \mathrm{ml}$ of protein-containing drink (60.0 \% energy as protein, $12.6 \%$ energy as fat and $11.6 \%$ energy as carbohydrate; $0.34 \mathrm{MJ}$ ) at $2^{\circ} \mathrm{C}$ or $60^{\circ} \mathrm{C}$ in the exercise + cold drink and exercise + hot drink trials, respectively. The proteincontaining drink contained $300 \mathrm{ml}$ of water mixed with $21 \mathrm{~g}$ of protein powder composed of $2.9 \mathrm{~g}$ of carbohydrate, $15.0 \mathrm{~g}$ of protein and $1.2 \mathrm{~g}$ of fat (SAVAS whey protein 100; Meiji Co. Ltd). Temperature of protein-containing drink was measured using an electric thermometer (testo 106; Testo K.K.). A volume of $300 \mathrm{ml}$ was chosen for the protein-containing drink because this volume was shown to delay gastric emptying in the previous study ${ }^{(15)}$. In the exercise trial, subjects sat on a chair in a fixed position for the same amount of time as they consumed the designated drink (i.e. $5 \mathrm{~min}$ ). Subjects then sat on a chair in a fixed position (i.e. the angle between the upper and lower part of the body was approximately $120^{\circ}$ ) in the laboratory for $30 \mathrm{~min}$ (09.35-10.05) in all trials. The subjects were then asked to consume the test meal from 10.05 and were instructed to eat as much as they feel satisfied until 11.05 in all trials. The 30-min interval between ingesting the protein-containing drink and subsequent meal was chosen because a previous study that has examined the effects of drink temperatures at $4^{\circ} \mathrm{C}, 37^{\circ} \mathrm{C}$ and $50^{\circ} \mathrm{C}$ on gastric motility over $60 \mathrm{~min}$ reported greater pyloric motility was observed in the $50^{\circ} \mathrm{C}$ drink than the $2{ }^{\circ} \mathrm{C}$ drink in the first 30 min after consumption of the drinks ${ }^{(16)}$. A $2 \mathrm{D}$ ultrasound scan was performed to assess the change in the cross-sectional pyloric antral area and gastric contractions at 09.00, 09.35, 09.45, 09.55 and 10.05 . Venous blood samples were collected by venepuncture at $09.00,09.35,10.05$ and 10.35 with subjects placed in a seated position to analyse plasma glucose, plasma insulin, plasma acylated ghrelin, plasma peptide YY (PYY) and serum NEFA concentrations. Subjects also completed a $100-\mathrm{mm}$ visual analogue scale using a paper-based questionnaire ${ }^{(17)}$, which assessed the subjective perceptions of appetite and feelings of stomach condition at 09.00, 09.35, 10.05 and 10.35.

\section{Subjective appetite perceptions and energy intake}

A prior written survey ensured the acceptability of the test meal; cereal (i.e. $9.7 \%$ energy as protein, $20.5 \%$ energy as fat and $69.8 \%$ energy as carbohydrate) and milk (i.e., $19 \cdot 8 \%$ energy as protein, $51 \cdot 1 \%$ energy as fat and $29 \cdot 1 \%$ energy as carbohydrate) were selected as the test meal at 10.05. Subjects were instructed to eat using a small bowl until they felt comfortably full and satisfied, and that additional food was available if desired $^{(18)}$. The test meal was prepared in excess of expected consumption on the table so that the subjects do not need to ask experimenters for serving additional food and was served in a feeding booth in the laboratory to remove outside distractions. During the trials, the subjects and experimenters were instructed to refrain from talking about the food. Drinking water was prohibited while the subjects were consuming the test meal.
The upper limit of meal intake time was set at $1 \mathrm{~h}$, referring to a previous study that examined the effects of pre-meal water intake on energy intake ${ }^{(10)}$, and mean time to consume the test meal in the exercise, exercise + cold drink and exercise + hot drink trials was 25.5 (SD 6.5), 23.1 (sD 4.5) and 15.5 (SD 4.3) min, respectively. The total amount of food intake $(\mathrm{g})$ was ascertained by examining the weighted difference in the test meal remaining than that initially presented. The total energy intake from the test meal was calculated using manufacture-reported values. Subjects completed visual analogue scale ${ }^{(17)}$ at 09.00, 09.35, 10.05 and 10.35 to assess their perceptions of appetite (i.e. hunger, fullness and desire to eat sweet, sour, fatty and salty foods). Also, subjects completed another visual analogue scale at 09.00, $09.35,10.05$ and 10.35 to assess the perceptions of feelings of stomach condition (i.e., 'Does your stomach feel uncomfortable?', 'Do you feel your stomach is expanding?' and 'Do you want to eat now?'). The verbal anchors 'not at all' and 'extremely' were placed at 0 and $100 \mathrm{~mm}$ on visual analogue scale, respectively.

\section{Assessment of gastric motility and blood flow}

Several previous studies suggest that the antrum is the most suitable area to evaluate the stomach capacity (for a review of this, see Van de Putte et al. $\left.{ }^{(19)}\right)$. Pyloric antral area measurements were performed using a 2D ultrasound machine (LOGIQ-e; GE Healthcare) and a 5.0 MHz sector transducer. All metals were removed from the surrounding area to avoid the possibility of interference during acquisition. To optimise precision, the transducer was positioned vertically to obtain a parasagittal image of the pyloric antrum, with the superior mesenteric vein and the abdominal aorta in a longitudinal section, as described previously ${ }^{(19)}$. After obtaining these signals for measuring pyloric antral area for $1 \mathrm{~min}$ at 09.00, 09.35, 09.45, 09.55 and 10.05, the pyloric antral area $\left(\mathrm{cm}^{2}\right)$ was determined using an image-editing software (ImageJ 1.47; National Institute of Mental Health). The gastric contractions of the pyloric antral area were defined as the frequency of contractions per $1 \mathrm{~min}$.

The mean blood velocities (MBV) and vessel diameters of the coeliac artery (CA), which supplies blood flow to the stomach, liver and spleen, and superior mesenteric artery (SMA) that supplies to the entire small intestine, proximal portions of the colon and the pancreas were measured. Simultaneously pulsed and echo-Doppler ultrasound flowmetry (LOGIQ-e; GE Healthcare) was used to measure MBV in and vessel diameters of the CA and SMA, as described previously ${ }^{(20)}$. A curvedarray Doppler scan probe operated a pulse Doppler frequency of 3.3 MHz (LOGIQ-e; GE Healthcare). The Doppler beam insonation angle relative to the blood vessel was maintained at $\leq 60^{\circ}$. After obtaining these signals for the measurement of MBV for 1 min, a cross-sectional image of the vessel was recorded for $30 \mathrm{~s}$. This process was performed at 09.00, 09.35, 09.45, 09.55 and 10.05. The HR and MBV were sampled at $20 \mathrm{kHz}$ using an A/D converter (PowerLab 8/30; ADInstruments). The spectra of the MBV signals were analysed offline using our Doppler signal processing software, and beat-by-beat MBV values were calculated. MBV was determined by averaging the ten largest values per min to eliminate respiration-induced data variations. The 
images sent from the Doppler monitor were videotaped to enable later measurement of the pyloric antral area and vessel diameters using image-editing software (ImageJ 1.47; National Institute of Mental Health). The MBV of CA and SMA were calculated as $\pi \cdot r^{2} \cdot \mathrm{MBV} \times 60$, where $r$ is the radius of the artery. The same technician measured all gastric measurements (i.e. MBV of CA and SMA, pyloric antral area and gastric contractions) to minimise measurement errors. CV for gastric motility and blood flow were $0.5 \%$ for pyloric antral area, $0.6 \%$ for gastric contractions of the pyloric antral area, $0.6 \%$ for MBV of CA and $0.6 \%$ for MBV of SMA.

\section{Biochemical analysis}

For serum NEFA, venous blood samples were collected into tubes containing clotting activators for serum isolation. The collected samples were allowed to clot for $30 \mathrm{~min}$ at room temperature and then centrifuged at $1861 \boldsymbol{g}$ for $10 \mathrm{~min}$ at $4^{\circ} \mathrm{C}$. Serum was removed, divided into aliquots and stored at $-80^{\circ} \mathrm{C}$ for later analysis. For plasma glucose, insulin and PYY measurements, venous blood samples were collected into sodium fluorideEDTA tubes. The tubes were immediately centrifuged and treated as above. For plasma acylated ghrelin, venous blood samples were collected into EDTA tubes containing aprotinin to prevent degradation of ghrelin by protease. The tube was immediately centrifuged, and $100 \mu \mathrm{l}$ of plasma was removed and was transferred into a tube containing $10 \mu \mathrm{l}$ of hydrochloric acid. The sample was stored at $-80^{\circ} \mathrm{C}$ for later analysis. Enzymatic, colorimetric assays were used to measure serum NEFA (NEFAHR; Wako Pure Chemical Industries, Ltd) and plasma glucose (GLU-HK(M); Shino-Test Corporation). ELISA was used to measure plasma acylated ghrelin (N750; SCETI K.K) and PYY (YK080; Yanaihara Institute Inc.).

\section{Statistical analysis}

The sample size was estimated with $G^{*}$ Power $3.1^{(21)}$, using the data from a previous cross-over study that investigated the effects of pre-meal fluid intake on energy intake ${ }^{(10)}$. A sample size of $\geq 5$ subjects was required to detect energy intake with a power of $80 \%$ and an $\alpha$ level of $5 \%$. However, gastric motility varies among individuals ${ }^{(22)}$, and the magnitude changes in gastric motility influence subsequent energy intake ${ }^{(10)}$. Therefore, we set our sample size to 12 based on our previous study that examined the changes in pre-meal water intake and gastric motility ${ }^{(23)}$. Data were analysed using the Predictive Analytics Software (PASW) version 23.0 for Windows (IBM SPSS Statistics 23.0; SPSS Japan Inc.). The Shapiro-Wilk test was used to check for the normality of distribution; all parameters were normally distributed. Repeated-measures one-factor ANOVA was used to assess differences among the three trials in energy intake and the length of meal. Repeated-measures, two-factor ANOVA was used to examine differences over time among the three trials in the cross-sectional pyloric antral area, frequency of gastric contractions, splanchnic blood flow, subjective appetite perceptions (i.e. hunger, fullness and desire to eat sweet, sour, fatty and salty foods) and subjective perception of the stomach. Where significant trial-time interactions and trial effects were found, the values were subsequently analysed with post hoc analysis for multiple comparisons using the Bonferroni method. The correlation coefficients were determined by using Pearson's product-moment tests between the frequency of gastric contractions and energy intake. The $95 \%$ CI for the mean absolute pairwise differences among the three trials were calculated using the t-distribution and degrees of freedom $(n-1)$. Effect sizes (ES) (Cohen's $d$ ) were calculated to describe the magnitude of difference between trials. Effect sizes of 0.2 are considered the minimum important difference in all outcome measures, 0.5 moderate and 0.8 large $^{(24)}$. Data were expressed as means and standard deviations. Statistical significance was set at $P<0.05$.

\section{Results}

\section{Dietary and physical activity data}

The mean energy intake $15 \mathrm{~h}$ before each trial was 3.4 (SD 1·3) MJ. Subjects weighed and recorded all dietary intakes in the $15 \mathrm{~h}$ before the first trial, and these dietary intakes were subsequently replicated in the $15 \mathrm{~h}$ preceding the second and third trials. The food diary analyses of food diaries revealed that energy intake was the same in the $15 \mathrm{~h}$ preceding each trial. The energy intake equated to $36(\mathrm{sD} 24) \%(36.7(\mathrm{sD} 30 \cdot 7) \mathrm{g} / \mathrm{d})$ from fat, $41(\mathrm{sD} 24) \%$ $(99 \cdot 7(\mathrm{sD} 40 \cdot 8) \mathrm{g} / \mathrm{d})$ from carbohydrates and $14(\mathrm{sD} 6) \%$ $(30 \cdot 8(\mathrm{sD} 15 \cdot 0) \mathrm{g} / \mathrm{d})$ from protein. The step counts, frequencies for light (levels 1-3) physical activity, moderate (levels 4-6) physical activity and vigorous (levels 7-9) physical activity recorded the day before each trial did not differ significantly among the trials (Table 2).

\section{Pre-trial}

There were no significant differences in body mass among the exercise, exercise + cold drink and exercise + hot drink trials at 09.00 (i.e. pre-trial). At pre-trial, subjective appetite perceptions (i.e. fullness and desire to eat sweet, sour, fatty and salty foods) and perception of the stomach did not differ among the trials. Subjective appetite perception of hunger at the pre-trial differed among the trials. Post hoc analyses revealed no significant differences between trials $(P>0 \cdot 05)$. Cross-sectional pyloric antral areas and frequency of gastric contractions were also not different at 09.00 (i.e. pre-trial) among the trials. MBV of CA and SMA were also not different at 09.00 (i.e. pre-trial) among the trials. There were no significant differences in glucose, NEFA, insulin, acylated ghrelin and PYY concentrations at the pre-trial among the trials. The body mass, fasting values for perception of the appetite and stomach, cross-sectional pyloric antral areas, frequency of gastric contractions, MBV of CA and SMA, glucose, NEFA, insulin, acylated ghrelin and PYY are shown in Table 2.

\section{Exercise responses}

There were no differences in mean HR (161 (SD 12) $v$. 161 (sD 15) v. 162 (sD 14) bpm for the exercise, exercise + cold drink and exercise + hot drink trials, respectively, ES $=0.007$, $P>0.05$ ) and ratings of perceived exertion (14 (SD 2) $v$. 
Table 2. Pre-trial physical activity, anthropometric, biochemical and perception of appetite and stomach values† (Mean values and standard deviations, $n=12$ )

\begin{tabular}{|c|c|c|c|c|c|c|c|}
\hline & \multicolumn{2}{|c|}{ EX } & \multicolumn{2}{|c|}{ EX + Cold } & \multicolumn{2}{|c|}{$\mathrm{EX}+\mathrm{Hot}$} & \multirow[b]{2}{*}{$P$} \\
\hline & Mean & SD & Mean & SD & Mean & SD & \\
\hline \multicolumn{8}{|l|}{ Physical activity the day before each trial } \\
\hline Step counts (steps/d) & 7264 & 2944 & 9523 & 4557 & 9659 & 2425 & NS \\
\hline Light (levels $1-3)$ physical activity (min/d) & 59 & 36 & 55 & 33 & 42 & 20 & NS \\
\hline Moderate (levels 4-6) physical activity (min/d) & 29 & 25 & 32 & 28 & 29 & 16 & NS \\
\hline Vigorous (levels 7-9) physical activity (min/d) & 2 & 2 & 3 & 4 & 2 & 1 & NS \\
\hline \multicolumn{8}{|l|}{ Body mass } \\
\hline Body mass (kg) & $65 \cdot 6$ & $6 \cdot 1$ & $65 \cdot 1$ & $6 \cdot 0$ & $65 \cdot 1$ & $5 \cdot 8$ & NS \\
\hline \multicolumn{8}{|l|}{ Perception of the appetite } \\
\hline Hunger (mm) & $73 \cdot 3$ & $22 \cdot 7$ & 61.5 & $22 \cdot 9$ & $71 \cdot 8$ & $23 \cdot 4$ & $0.011^{\star}$ \\
\hline Fullness $(\mathrm{mm})$ & $11 \cdot 3$ & 8.4 & $19 \cdot 2$ & $12 \cdot 9$ & $13 \cdot 0$ & $11 \cdot 1$ & NS \\
\hline Desire to eat sweet foods (mm) & $62 \cdot 7$ & $28 \cdot 8$ & $57 \cdot 5$ & $28 \cdot 3$ & $60 \cdot 8$ & $28 \cdot 7$ & NS \\
\hline Desire to eat sour foods (mm) & 41.5 & $28 \cdot 4$ & $29 \cdot 6$ & $26 \cdot 4$ & $34 \cdot 8$ & $34 \cdot 3$ & NS \\
\hline Desire to eat fatty foods (mm) & $39 \cdot 3$ & $32 \cdot 9$ & $36 \cdot 7$ & $30 \cdot 3$ & $43 \cdot 8$ & $34 \cdot 0$ & NS \\
\hline Desire to eat salty foods (mm) & $56 \cdot 8$ & $31 \cdot 8$ & $46 \cdot 0$ & $29 \cdot 6$ & $57 \cdot 7$ & $30 \cdot 4$ & NS \\
\hline \multicolumn{8}{|l|}{ Perception of stomach } \\
\hline Feeling of stomach (mm) & $30 \cdot 6$ & $29 \cdot 8$ & $25 \cdot 8$ & $23 \cdot 8$ & $26 \cdot 8$ & $30 \cdot 9$ & NS \\
\hline Stomach expansion (mm) & $20 \cdot 3$ & $25 \cdot 6$ & $20 \cdot 6$ & 24.5 & $21 \cdot 2$ & $24 \cdot 3$ & NS \\
\hline Desire to eat food (mm) & $72 \cdot 4$ & $27 \cdot 1$ & $65 \cdot 7$ & 23.4 & $71 \cdot 2$ & $26 \cdot 8$ & NS \\
\hline \multicolumn{8}{|l|}{ Gastric motility } \\
\hline Cross-sectional pyloric antral areas $\left(\mathrm{cm}^{2}\right)$ & 3.4 & 0.8 & $3 \cdot 9$ & $1 \cdot 2$ & $3 \cdot 8$ & 0.8 & NS \\
\hline Frequency of gastric contractions (times/min) & 0.9 & 0.7 & $1 \cdot 3$ & $0 \cdot 8$ & $1 \cdot 3$ & 0.4 & NS \\
\hline \multicolumn{8}{|l|}{ Gastric blood flow } \\
\hline Mean blood velocities of coeliac artery $(\mathrm{ml} / \mathrm{min})$ & $116 \cdot 6$ & $77 \cdot 7$ & $113 \cdot 8$ & $71 \cdot 3$ & $138 \cdot 7$ & $57 \cdot 1$ & NS \\
\hline Mean blood velocities of superior mesenteric artery $(\mathrm{ml} / \mathrm{min})$ & $97 \cdot 1$ & $68 \cdot 1$ & 91.4 & $44 \cdot 3$ & $126 \cdot 4$ & $66 \cdot 0$ & NS \\
\hline \multicolumn{8}{|l|}{ Blood concentrations } \\
\hline Glucose $(\mathrm{mmol} / \mathrm{l})$ & $4 \cdot 6$ & 0.4 & $4 \cdot 8$ & 0.3 & 4.9 & 0.3 & NS \\
\hline NEFA (mmol/l) & 0.4 & $0 \cdot 2$ & 0.3 & $0 \cdot 1$ & 0.4 & $0 \cdot 1$ & NS \\
\hline Insulin (pmol/l) & $17 \cdot 4$ & $8 \cdot 8$ & $22 \cdot 4$ & $11 \cdot 6$ & $19 \cdot 2$ & $9 \cdot 9$ & NS \\
\hline Acylated ghrelin (pg/ml) & 61.4 & $17 \cdot 6$ & $60 \cdot 3$ & $15 \cdot 2$ & $57 \cdot 4$ & $16 \cdot 0$ & NS \\
\hline Peptide YY (pg/ml) & $789 \cdot 9$ & $326 \cdot 2$ & 789.9 & $326 \cdot 2$ & $855 \cdot 0$ & $493 \cdot 5$ & NS \\
\hline
\end{tabular}

EX, running for $30 \mathrm{~min}$ at $80 \%$ of maximum heart rate; Cold, $300 \mathrm{ml}$ of protein-containing drink intake at $2^{\circ} \mathrm{C}$; Hot, $300 \mathrm{ml}$ of protein-containing drink intake at $60^{\circ} \mathrm{C}$. ${ }^{*}$ No significant differences between trials $(P>0.05)$.

† Data were analysed using one-factor ANOVA.

$14(\mathrm{SD} 2) v .14$ (SD 2) for the exercise, exercise + cold drink and exercise + hot drink trials, respectively, $\mathrm{ES}=0.049, P>0.05$ ) during the treadmill running among the trials.

\section{Energy intake}

Energy intake differed among the trials (6.5 (SD 2.1) MJ $v$. 6.1 (sD 2.1) MJ $v \cdot 7 \cdot 5(\mathrm{sD} 2 \cdot 5) \mathrm{MJ}$ for the exercise, exercise + cold drink and exercise + hot drink trials, respectively; main effect of trial, ES $=0.501, P<0.001)$. Post hoc tests revealed that energy intake in the exercise + hot drink trial was $14 \%$ and $15 \%$ higher than the exercise $(P=0 \cdot 046,95 \%$ CI $4 \cdot 010,482 \cdot 538)$ and exercise + cold drink $(P=0 \cdot 001,95 \%$ CI 160.089, 517.111) trials, respectively (Fig. 1). The amount of cereal (282.2(sD 87.8) g $v$. 269.3 (sD 95.7) g $v .338 .2(\mathrm{sD} 133.4) \mathrm{g}$ for the exercise, exercise + cold drink and exercise + hot drink trials, respectively; main effect of trial, $\mathrm{ES}=0.462, P=0.001)$ consumed also differed among trials. The amount of milk consumed did not differ among trials (694.6 (sD 317.5) $\mathrm{ml} v \cdot 627 \cdot 1$ (sD 256.2) $\mathrm{ml} v \cdot 739 \cdot 1$ (sD 264.4) $\mathrm{ml}$ for the exercise, exercise + cold drink and exercise + hot drink trials, respectively; main effect of trial, ES $=0.201, P>0.05$ ). There was no difference in the average time taken to feel comfortably full (25.5 (SD 6.5) min, 23.1 (SD 4.5) min and 23.9 (SD 6.1) min for the exercise, exercise + cold drink and exercise + hot drink trials, respectively; $\mathrm{ES}=0 \cdot 162, P>0 \cdot 05)$ among the trials.

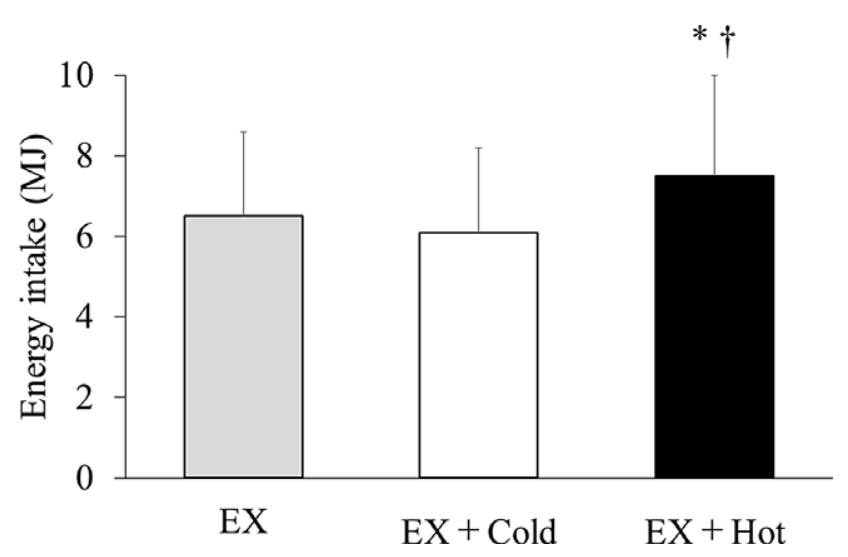

Fig. 1. Energy intake at test meal. Data are mean \pm SD. Mean was compared using one-factor ANOVA for the main effect of trial followed by a multiple comparison test using the Bonferroni method. EX, running for $30 \mathrm{~min}$ at $80 \%$ of maximum heart rate; Cold, $300 \mathrm{ml}$ of protein-containing drink intake at $2^{\circ} \mathrm{C}$; Hot, $300 \mathrm{ml}$ of protein-containing drink intake at $60^{\circ} \mathrm{C}$. *Significantly different between the EX and EX + Hot trials $(p<0.05)$. †Significantly different between the EX + Cold and EX + Hot trials $(p<0.05)$.

\section{Subjective appetite perceptions}

There were no significant differences in subjective appetite perceptions (i.e. hunger, fullness and desire to eat sweet, sour, fatty 
and salty foods) or perceptions of the stomach (i.e. 'Dose your stomach feel uncomfortable?', 'Do you feel your stomach is expanding?' and 'Do you want to eat now?') among the trials $(P>0 \cdot 05)$.

\section{Gastric antral area and gastric motility}

For the cross-sectional pyloric antral areas, there were trial-time interactions ( $\mathrm{ES}=0.372, P=0 \cdot 011$ ). Cross-sectional pyloric antral areas increased in the exercise + cold drink and exercise + hot drink trials compared with the exercise trial at 09.35 (i.e. after exercise) $\left(4.3(\mathrm{sD} 2.1) \mathrm{cm}^{2} v .7 .9(\mathrm{sD} 3.5) \mathrm{cm}^{2} v \cdot 9 \cdot 8(\mathrm{sD} 3.7)\right.$ $\mathrm{cm}^{2}$ for the exercise, exercise + cold drink and exercise + hot drink trials, respectively; exercise $v$. exercise + cold drink: $P=0.024,95 \%$ CI $0.804,8.431$, exercise hot $v$. exercise + hot drink: $P=0 \cdot 018,95 \%$ CI $1 \cdot 148,9 \cdot 205), 09.45$ (i.e. 15 min after exercise) $\left(4 \cdot 4(\mathrm{SD} 2 \cdot 1) \mathrm{cm}^{2} v \cdot 9 \cdot 0(\mathrm{SD} 2 \cdot 3) \mathrm{cm}^{2} v \cdot 9 \cdot 0(\mathrm{SD} 3 \cdot 2) \mathrm{cm}^{2}\right.$ for the exercise, exercise + cold drink and exercise + hot drink trials, respectively; exercise $v$. exercise + cold drink: $P=0.001$, $95 \%$ CI 3.350, 7.436, exercise $v$. exercise + hot drink: $P=0.004,95 \%$ CI $0 \cdot 146,8.361)$ and 09.55 (i.e. 25 min after exercise) (4.0 (sD 1.6) $\mathrm{cm}^{2} v .8 .0$ (sD 1.4) $\mathrm{cm}^{2} v .7 \cdot 2(\mathrm{sD} 2 \cdot 1) \mathrm{cm}^{2}$ for the exercise, exercise + cold drink and exercise + hot drink trials, respectively; exercise $v$. exercise + cold drink: $P=0.003$, $95 \%$ CI $2 \cdot 133,6.447$, exercise $v$. exercise + hot drink: $P=0.042$, $95 \%$ CI $0 \cdot 136,5 \cdot 676$ ) (Fig. 2). The frequency of gastric contractions differed significantly among the trials (main effect of trial, ES $=0.710, P=0.001)$. Post hoc analyses indicated that the frequency of gastric contractions in the exercise + hot drink trial was higher than the exercise $(P=0.023,95 \%$ CI $0 \cdot 176$, $1.938)$ and exercise + cold drink $(P=0.007,95 \%$ CI 0.370 , 1.801) trials (Fig. 3).

\section{Association between energy intake and frequency of the gastric contractions}

There was a positive relationship between energy intake from the test meal and the total frequency of gastric contractions when the data from all trials were pooled (i.e. exercise, exercise + cold drink and exercise + hot drink trials $)(r=0 \cdot 386, P=0 \cdot 022)$.

\section{Splanchnic blood flow}

There was no main effect of trial (ES $<0.001, P>0.05$ ), time (ES $=0.048, P>0.05)$ and trial-time interaction $(\mathrm{ES}=0.192$, $P>0.05)$ for blood flow in the CA. There were no main effects of trial $(\mathrm{ES}=0.315, P>0.05)$, time (ES $=0.474, P>0.05)$ and trial-time interaction $(\mathrm{ES}=0.389, P>0.05)$ for blood flow in the SMA.

\section{Blood concentrations}

The 2-h incremental AUC values for glucose, NEFA, insulin, acylated ghrelin and PYY are shown in Table 3. For the glucose, there was a main effect of time $(\mathrm{ES}=0.345, P=0.003)$. Post $h o c$ analysis indicated that glucose increased after exercise $(P<0.05)$. For the NEFA, there was a main effect of time $(\mathrm{ES}=0.885, P<0.001)$ and trial-time interactions $(\mathrm{ES}=0.338$, $P<0.001)$. Post hoc analysis revealed that NEFA did not differ between trials at all time points $(P>0 \cdot 05)$. For the insulin, there

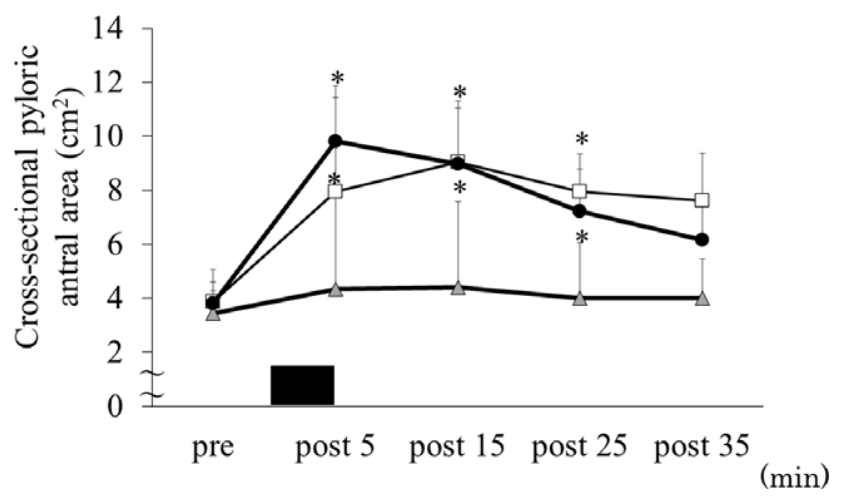

Fig. 2. Cross-sectional pyloric antral area before and after exercise. Data are mean \pm SD. Black rectangle indicates consuming $300 \mathrm{ml}$ of protein-containing drink in $5 \mathrm{~min}$. Data were analysed using two-factor ANOVA followed by a multiple comparison test using the Bonferroni method. EX, running for 30 min at $80 \%$ of maximum heart rate; Cold, $300 \mathrm{ml}$ of protein-containing drink intake at $2^{\circ} \mathrm{C}$; $\mathrm{Hot}, 300 \mathrm{ml}$ of protein-containing drink intake at $60^{\circ} \mathrm{C}$. There was a significant trial-time interaction $(p=0.011)$. ${ }^{*}$ Significantly different from EX trial $(p<0.05)$. -2. EX; 마, EX + Cold; —, EX + Hot.

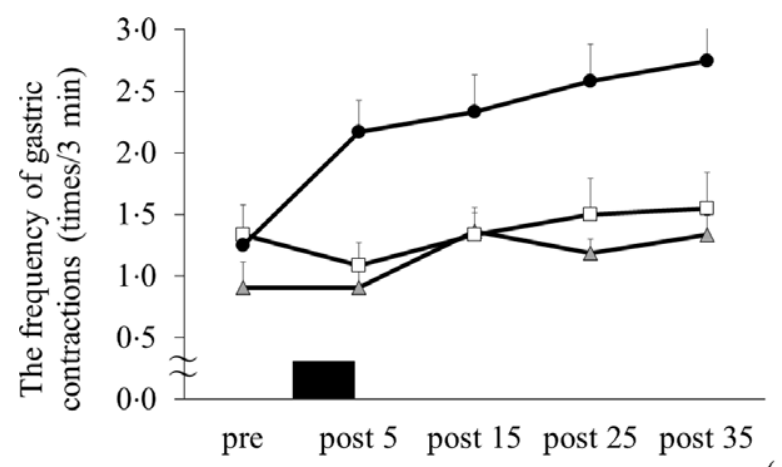

$(\min )$

Fig. 3. The frequency of gastric contractions before and after exercise. Data are mean \pm SD. Black rectangle indicates consuming $300 \mathrm{ml}$ of protein-containing drink in $5 \mathrm{~min}$. Data were analysed using two-factor ANOVA followed by a multiple comparison test using the Bonferroni method. EX, running for $30 \mathrm{~min}$ at $80 \%$ of maximum heart rate; Cold, $300 \mathrm{ml}$ of protein-containing drink intake at $2^{\circ} \mathrm{C}$; Hot, $300 \mathrm{ml}$ of protein-containing drink intake at $60^{\circ} \mathrm{C}$. There was a significant main effect of trial $(p=0.001) . \_, E X ; \square, E X+$ Cold; $\multimap$, EX + Hot.

was a main effect of trial (ES $=0 \cdot 338, P=0 \cdot 016)$. Post hoc analysis indicated that insulin tended to be higher in the exercise + cold drink $(P=0 \cdot 062,95 \% \mathrm{CI}-0 \cdot 257,11 \cdot 590)$ and exercise + hot drink $(P=0 \cdot 079,95 \% \mathrm{CI}-0 \cdot 867,17 \cdot 822)$ trials than the exercise trial. There were no between-trials differences for the acylated ghrelin. For the PYY, there was a main effect of time $(\mathrm{ES}=0.865, P<0 \cdot 001)$. Post hoc analysis revealed that PYY increased after exercise and the test meal.

\section{Discussion}

To our knowledge, the present study is the first to investigate how different temperatures of protein-containing drink after exercise influence gastric motility and subsequent energy intake in healthy men. The present study demonstrated that consuming $300 \mathrm{ml}$ of protein-containing drink at $60^{\circ} \mathrm{C}$ after $80 \%$ of $\mathrm{HR}_{\max }$ 
Table 3 Incremental AUC values of blood measurements over $2 \mathrm{~h} \dagger$

(Mean values and standard deviations, $n=12$ )

\begin{tabular}{|c|c|c|c|c|c|c|c|}
\hline & \multicolumn{2}{|c|}{ EX } & \multicolumn{2}{|c|}{ EX + Cold } & \multicolumn{2}{|c|}{$\mathrm{EX}+\mathrm{Hot}$} & \multirow[b]{2}{*}{$P$} \\
\hline & Mean & SD & Mean & SD & Mean & SD & \\
\hline Glucose (mmol/l per $2 \mathrm{~h}$ ) & $1 \cdot 1$ & 0.9 & 0.7 & 0.6 & 0.8 & 0.8 & NS \\
\hline NEFA (mmol/l per $2 \mathrm{~h})$ & 0.5 & 0.2 & 0.4 & 0.2 & 0.5 & 0.2 & NS \\
\hline Insulin (pmol// per $2 \mathrm{~h})$ & $132 \cdot 0$ & $69 \cdot 0$ & $209 \cdot 4^{*}$ & $71 \cdot 1$ & $261.6^{*}$ & $151 \cdot 6$ & 0.002 \\
\hline Acylated ghrelin (pg/ml per $2 \mathrm{~h})$ & $13 \cdot 0$ & $22 \cdot 3$ & $7 \cdot 8$ & $14 \cdot 4$ & $4 \cdot 7$ & 5.4 & NS \\
\hline Peptide YY (pg/ml per $2 \mathrm{~h})$ & 151.5 & $100 \cdot 3$ & $148 \cdot 1$ & $72 \cdot 4$ & $138 \cdot 1$ & $66 \cdot 4$ & NS \\
\hline
\end{tabular}

EX, running for $30 \mathrm{~min}$ at $80 \%$ of maximum heart rate; Cold, $300 \mathrm{ml}$ of protein-containing drink intake at $2^{\circ} \mathrm{C}$; Hot, $300 \mathrm{ml}$ of protein-containing drink intake at $60^{\circ} \mathrm{C}$.

${ }^{*}$ Different from the EX trial $(P<0.05)$.

$\dagger$ Data were analysed using one-factor ANOVA followed by a multiple comparison test using the Bonferroni method.

treadmill running increased subsequent ad libitum energy intake by $14 \%$ and $19 \%$ compared with no preload and consuming $300 \mathrm{ml}$ of protein-containing drink at $2^{\circ} \mathrm{C}$, respectively. The present study also showed that increased energy intake after consuming protein-containing drink at $60^{\circ} \mathrm{C}$ was accompanied by changes in gastric contractions. These findings add new knowledge to the literature, demonstrating that drink temperature may play an important role in modulating post-exercise gastric motility and subsequent energy intake. The inability to replenish the energy consumed by exercise from the diet after exercise can cause negative physical consequences, including delayed physical recovery. Our study provides useful information for improving appetite and can aid in proper energy replenishment after exercise.

Three laboratory-based studies have examined the effects of protein-containing drink ingestion on subsequent energy intake $^{(3-5)}$, with discrepancies in the results. Although three available studies examined the effect of post-exercise proteincontaining drink ingestion on energy intake in humans ${ }^{(3-5)}$, only one study has specified the temperature of water used in the study (i.e. about $\left.5^{\circ} \mathrm{C}\right)^{(4)}$. Alternatively, given the well-documented slower rate of gastric emptying and lower energy intake at cold water (i.e. at $2^{\circ} \mathrm{C}$ ) compared with warm water (i.e. at $37^{\circ} \mathrm{C}$ and $\left.60^{\circ} \mathrm{C}\right)^{(10)}$, the temperature of ingested protein-containing drink may be the proposed reason for the discrepant findings among the studies. In addition, oral sensations such as taste related to appetite ${ }^{(25)}$ are known to be affected by meal temperature, especially sweetness which increases in intensity with increasing temperature ${ }^{(26)}$. Although the present study did not measure the effects of different temperatures of protein-containing drinks on oral sensation, it may explain the differences in energy intake caused by drink temperatures.

Changes in gastric motility might be the most plausible reason why the different temperatures of protein-containing drink affected ad libitum energy intake. Gastric motility is known as a key mediator of appetite control ${ }^{(27)}$. Several previous studies have shown that gastric emptying and gastric motility can influence exercise-induced energy intake changes before and during exercise $^{(7)}$. The present study demonstrated that the gastric contraction increased after consuming a $300 \mathrm{ml}$ of proteincontaining drink at $60^{\circ} \mathrm{C}$ compared with other trials. There was a positive relationship between energy intake from the test meal and the frequency of the total gastric contractions. Moreover, our previous study demonstrated that consuming
$500 \mathrm{ml}$ of water at $37^{\circ} \mathrm{C}$ and $60^{\circ} \mathrm{C}$ increased subsequent energy intake compared with $500 \mathrm{ml}$ of water at $2^{\circ} \mathrm{C}$. Increased energy intake after consuming water at $37^{\circ} \mathrm{C}$ and $60^{\circ} \mathrm{C}$ was accompanied by a change in gastric contractions ${ }^{(10)}$. The temperature of a drink is known to be one of the major factors affecting gastric motility ${ }^{(8,16)}$. Two laboratory-based studies that investigated the effects of hot drink intake on gastric motility measured by electrogastrogram have demonstrated increased gastric contraction after consuming a hot drink $\left(50-55^{\circ} \mathrm{C}\right)$ compared with consuming cold drink or warm drink $\left(4-37^{\circ} \mathrm{C}\right)^{(8,16)}$. Although we measured gastric motility via an ultrasound imaging system instead of an electrogastrogram in the present study, our findings were similar to these previous studies ${ }^{(8,16)}$. Peristaltic motions of the stomach propagate due to induction by slow waves from the cardia to pyloric antral area and controlled gastric motility. Nakamura et al. collected the smooth muscle from guinea pigs and examined peristalsis changes with elevated temperature ${ }^{(28)}$. This study indicated that elevated the temperature from $24^{\circ} \mathrm{C}$ to $42^{\circ} \mathrm{C}$ increased the frequency and maximum rate of rising of the upstroke phase of slow waves ${ }^{(28)}$. Sun et al. reported that the temperature in the stomach reached $43^{\circ} \mathrm{C}$ after consuming 400 $\mathrm{ml}$ of orange juice at $50^{\circ} \mathrm{C}^{(29)}$. Based on these findings, a similar gastric temperature can be expected after consuming $300 \mathrm{ml}$ of protein-containing drink at $60^{\circ} \mathrm{C}$ in the present study. These results suggest that increased gastric motility might be caused by elevated gastric temperatures. Although the rate of gastric emptying is influenced by the fluid temperature ${ }^{(9,22,29)}$ and affects the subjective feeling of hunger ${ }^{(30)}$, the cross-sectional pyloric antral area, an indicator of gastric emptying, did not change between the protein-containing drink at $60^{\circ} \mathrm{C}$ and $2^{\circ} \mathrm{C}$ in the present study. These discrepancies observed between the present study and previous studies ${ }^{(9,22,29)}$ may be explained by the differences in the measurement condition (i.e. exercise or rest). Exercise is one of the factors that leads to delayed gastric emptying $^{(7)}$, and immediate post-exercise carbohydrate-protein drink ingestion delays gastric emptying compared with ingestion 30 min after exercise ${ }^{(15)}$. Therefore, gastric emptying is temporarily delayed after exercise ${ }^{(15)}$, and gastric emptying may be less affected by the temperature of drink after exercise. Another reason for the discrepant findings may be explained by the effects of sensory perceptions of the drinks. Although the macronutrients of drink (i.e. protein, fat and carbohydrate) are less effective for gastric emptying ${ }^{(31)}$, the differences in oral sensation, such as thickness and creaminess, due to differences in nutrients, affect 
gastric emptying rate ${ }^{(3)}$. In the present study, the thickness and creaminess of protein-containing drinks may have contributed to gastric emptying differences due to temperature. Future studies should examine the effect of the differences in oral sensations due to drink temperature on gastric emptying.

Several possible mechanisms explain how gastric contraction affects energy intake. First, appetite-regulating hormones secreted from the gastrointestinal tract might affect gastric contraction and/or energy intake ${ }^{(32)}$. However, in the present study, the trials did not differ in the concentrations of acylated ghrelin, a hormone that increases gastric contraction and enhances energy intake, and PYY which reduces gastric contraction and suppresses energy intake. Second, gastrointestinal blood flow, which is delivering appetite-regulating hormones, has been reported to decrease after high-intensity exercise and has been implicated as a contributing factor to anorexia after exercise ${ }^{(33)}$. However, after $30 \mathrm{~min}$ of running at $80 \%$ of $\mathrm{HR}_{\max }$ conducted in the present study, the blood flow in the SMA and CA, which are represented by gastrointestinal blood flow, did not change. Also, the gastrointestinal blood flow was not affected by the different temperatures of the consumed drink after exercise. These results suggest that gastrointestinal blood flow has little effect on the increase in energy intake from hot protein-containing drinks ingested after exercise. Collectively, our findings suggest that increased mechanical gastric contractions other than appetiteregulating hormones and gastrointestinal blood flow may play an important role in increased energy intake.

The present study has several strengths. We examined the effects of different temperatures of protein-containing drinks on both gastric motility and energy intake. The macronutrient content of drinks, ambient temperature and the amount of water taken during exercise are often considered factors for the influence of exercise on energy intake ${ }^{5,7,34,35)}$. To our knowledge, the present study is the first to examine the effects of different temperatures of protein-containing drinks after exercise on subsequent energy intake. Moreover, we have tried to address the role of gastric motility, a potential mechanism underpinning the modulation of energy intake, in energy intake after exercise. Therefore, the present findings may provide important insight into the role that the drink temperature plays in modulating energy intake after exercise. Although future research is needed to examine the effects of palatability, easiness and taste which are associated with drink temperature on feelings of appetite and energy intake in order to evaluate the practical relevance of warm drink in daily exercise, the results of the present study indicate that hot meals such as hot drinks and hot soups may be useful as one of the methods of post-exercise nutrient ingestion to enhance appetite. However, the present study has several limitations. First, energy intake, appetite-regulating hormones, gastric motility and gastrointestinal blood flow were assessed for lasting approximately $2 \mathrm{~h}$. These variables may need to be assessed over a more extended period to detect the effects of different temperatures of proteincontaining drink after exercise, if any, on appetite. Second, we did not provide water to subjects during the meal to avoid stomach distention caused by water intake, and this lack of water might affect energy intake after exercise ${ }^{(36)}$. Another limitation is the generalisability of our study since this study examined the acute effect of the pre-meal drink volume on gastric motility and energy intake in healthy individuals. Further studies should examine the chronic effects in various populations, including different age groups and health conditions.

In conclusion, consuming $300 \mathrm{ml}$ of protein-containing drink at $60^{\circ} \mathrm{C}$ after $80 \%$ of $\mathrm{HR}_{\max }$ treadmill running increased gastric contractions and ad libitum energy intake compared with no preload and an identical drink at $2^{\circ} \mathrm{C}$ after $80 \%$ of $\mathrm{HR}_{\text {max }}$ treadmill running in healthy young men. Therefore, the post-exercise consumption of hot drinks is useful for post-exercise appetite enhancement.

\section{Acknowledgements}

This study was supported by the Japan Society of Promotion for Science (grant number 18J12735) and the Human Performance Laboratory, Organization for University Research Initiatives, Waseda University (grant number 2019-8). We wish to express our gratitude to all individuals who participated in our study.

K. F. supervised the data collection, performed the data analysis and interpretation and wrote the manuscript. Y. H. and M. H. assisted with all aspects of the data collection. K. S. advised the data analysis and interpretation to K. F. and revised the manuscript. M. M. conceived the study, advised the data analysis and interpretation to K. F. and revised the manuscript. All authors approved the final version of the manuscript.

All authors declare that there is no conflict of interest.

\section{References}

1. Thomas DT, Erdman KA \& Burke LM (2016) American college of sports medicine joint position statement. Nutrition and athletic performance. Med Sci Sport Exerc 48, 543-568.

2. Jäger R, Kerksick CM, Campbell BI, et al. (2017) International society of sports nutrition position stand: protein and exercise. J Int Soc Sports Nutr 14, 20.

3. Monteyne A, Martin A, Jackson L, et al. (2018) Whey protein consumption after resistance exercise reduces energy intake at a post-exercise meal. Eur J Nutr 57, 585-592.

4. Rumbold P, Shaw E, James L, et al. (2015) Milk consumption following exercise reduces subsequent energy intake in female recreational exercisers. Nutrients 7, 293-305.

5. Clayton DJ, Stensel DJ, Watson P, et al. (2014) The effect of post-exercise drink macronutrient content on appetite and energy intake. Appetite 82, 173-179.

6. Burdon CA, O'Connor HT, Gifford JA, et al. (2010) Influence of beverage temperature on exercise performance in the heat: a systematic review. Int J Sport Nutr Exerc Metab 20, $166-174$.

7. Horner KM, Schubert MM, Desbrow B, et al. (2015) Acute exercise and gastric emptying: a meta-analysis and implications for appetite control. Sport Med 45, 659-678.

8. Verhagen MAMT, Luijk HD, Samsom M, et al. (1998) Effect of meal temperature on the frequency of gastric myoelectrical activity. J Neurogastroenterol Motil 10, 175-181.

9. Mishima Y, Amano Y, Takahashi Y, et al. (2009) Gastric emptying of liquid and solid meals at various temperatures. $J$ Gastroenterol 44, 412-418.

10. Fujihira K, Hamada Y, Yanaoka T, et al. (2020) The effects of water temperature on gastric motility and energy intake in healthy young men. Eur J Nutr 59, 103-109. 
11. Holtzman B \& Ackerman KE (2019) Measurement, determinants, and implications of energy intake in Athletes. Nutrients 11, 665.

12. Kumahara H, Schutz Y, Ayabe M, et al. (2004) The use of uniaxial accelerometry for the assessment of physicalactivity-related energy expenditure: a validation study against whole-body indirect calorimetry. Br J Nutr 91, 235-243.

13. Taylor HL, Buskirk E \& Henschel A (1955) Maximal oxygeniIntake as an objective measure of cardio-respiratory performance. J Appl Physiol 8, 73-80.

14. Borg GA (1973) Perceived exertion: a note on 'history' and methods. Med Sci Sport Exerc 5, 90-93.

15. Kashima H, Harada N, Miyamoto K, et al. (2017) Timing of postexercise carbohydrate-protein supplementation: roles of gastrointestinal blood flow and mucosal cell damage on gastric emptying in humans. J Appl Physiol 123, 606-613.

16. Sun WM, Penagini R, Hebbard G, et al. (1995) Effect of drink temperature on antropyloroduodenal motility and gastric electrical activity in humans. Gut 37, 329-334.

17. Flint A, Raben A, Blundell JE, et al. (2000) Reproducibility, power and validity of visual analogue scales in assessment of appetite sensations in single test meal studies. Int $J$ Obes Relat Metab Disord 24, 38-48.

18. Ueda SY, Yoshikawa T, Katsura Y, et al. (2009) Comparable effects of moderate intensity exercise on changes in anorectic gut hormone levels and energy intake to high intensity exercise. J Endocrinol 203, 357-364.

19. Van De Putte P \& Perlas A (2014) Ultrasound assessment of gastric content and volume. BrJ Anaesth 113, 12-22.

20. Hamada Y, Kashima H \& Hayashi N (2014) The number of chews and meal duration affect diet-induced thermogenesis and splanchnic circulation. Obesity 22, E62-E69.

21. Faul F, Erdfelder E, Lang AG, et al. (2007) G*Power 3: a flexible statistical power analysis program for the social, behavioral, and biomedical sciences. Behav Res Meth 39, 175-191.

22. Bateman DN (1982) Effects of meal temperature and volume on the emptying of liquid from the human stomach.JPhysiol 331, 461-467.

23. Fujihira K, Hamada Y, Suzuki K, et al. (2020) The effects of premeal drink volume on gastric motility and energy intake in healthy men. Physiol Behav 213, 112766.
24. Cohen J (1988) Statistical Power Analysis for the Behavioural Sciences. Mahwah: Lawrence Erlbaum Assoc.

25. Yin W, Hewson L, Linforth R, et al. (2017) Effects of aroma and taste, independently or in combination, on appetite sensation and subsequent food intake. Appetite 114, 265-274.

26. Green BG (1993) Heat as a factor in the perception of taste, smell, and oral sensation. In Nutritional Needs in Hot Environments: applications for Military Personnel in Field Operations, pp. 173-186 [Marriott BM, editor]. Washington, DC: National Academies Press.

27. Janssen P, Vanden Berghe P, Verschueren S, et al. (2011) Review article: the role of gastric motility in the control of food intake. Aliment Pharmacol Ther 33, 880-894.

28. Nakamura E, Kito Y, Hashitani H, et al. (2006) Metabolic component of the temperature-sensitivity of slow waves recorded from gastric muscle of the guinea-pig. J Smooth Muscle Res 42, 33-48.

29. Sun WM, Houghton LA, Read NW, et al. (1988) Effect of meal temperature on gastric emptying of liquids in man. Gut $\mathbf{2 9}$, 302-305.

30. Bergmann JF, Chassany O, Petit A, et al. (1992) Correlation between echographic gastric emptying and appetite: Influence of psyllium. Gut 33, 1042-1043.

31. Goetze O, Steingoetter A, Menne D, et al. (2007) The effect of macronutrients on gastric volume responses and gastric emptying in humans: a magnetic resonance imaging study. $\mathrm{Am} \mathrm{J}$ Physiol 292, G11-17.

32. Guyton AC \& Hall J (1996) General principles of gastrointestinal function: motility, nervous control, and blood circulation. In Textbook of Medical Physiology, 9 ed. Philadelphia: Saunders.

33. Hazell TJ, Islam H, Townsend LK, et al. (2016) Effects of exercise intensity on plasma concentrations of appetite-regulating hormones: potential mechanisms. Appetite 98, 80-88.

34. Halse RE, Wallman KE \& Guelfi KJ (2011) Postexercise water immersion increases short-term food intake in trained men. Med Sci Sport Exerc 43, 632-638.

35. Kojima C, Kasai N, Kondo C, et al. (2018) Post-exercise whole body cryotherapy $\left(-140^{\circ} \mathrm{C}\right)$ increases energy intake in athletes. Nutrients 10, 893.

36. Pérez-Luco C, Díaz-Castro F, Jorquera C, et al. (2019) Fluid restriction decreases solid food consumption post-exercise. Nutrients 11, 1209. 